\title{
Flocculation of hyphae is associated with a deletion in the putative CaHK1 two-component histidine kinase gene from Candida albicans
}

\author{
José Antonio Calera and Richard Calderone
}

Department of Microbiology and Immunology, Georgetown University Medical Center, 3900 Reservoir Road NW, Washington DC 20007-2197, USA

\author{
Author for correspondence: José Antonio Calera. Tel: +1 202687 1796. Fax: + 12026871800 \\ e-mail : caleraaj $(a$ medlib.georgetown.edu
}

In Candida albicans, three putative histidine kinase genes have been described thus far, including CaSLN1, CaNIK1/COS1 and CaHK1. The encoded proteins for C. albicans, CaSln1p and CaNik1p, which are similar to SIn1p from Saccharomyces cerevisiae and Nik-1 from Neurospora crassa, seem to function in osmoregulation and morphogenesis, respectively. Recently, the isolation of CaHK1, a putative histidine kinase gene from $C$. albicans has been reported. In addition to the histidine and aspartyl domains located at its C-terminus as previously described, it is shown here that the $\mathrm{N}$-terminal domain of Cahk1p contains a P-loop motif and a sequence which shows significant homology with the seven C-terminal domains of serine/threonine kinases. The Ser/Thrhomologous domains of Cahk1p could, in fact, correspond to its sensor sequence. CaHK1 has been mapped to chromosome 2 and gene deletion studies were undertaken to understand its function. $\Delta$ cahk1 mutants are phenotypically different from any other histidine kinase mutants thus far described either in C. albicans or in any other yeast or filamentous fungus. This study demonstrates that $\Delta$ cahk 1 mutants flocculate extensively in a genedosage-dependent manner under conditions which induce germ-tube formation, such as growth in medium 199 (pH 7.5). The flocculation occurs by an interaction along the hyphal surfaces, probably because of the altered expression of one or more hyphal-cell-surface components in the $\Delta$ cahk 1 mutants. These results indicate that $\mathrm{CaHK1}$ could be involved in regulating their expression.

Keywords: Flocculation, histidine kinase, two-component, hyphae, Candida albicans

\section{INTRODUCTION}

The sensor histidine kinases and their corresponding response regulators were first described in prokaryote phosphotransfer pathways which enable cells to detect environmental changes and elicit an adaptive response (Hoch \& Silhavy, 1995). More recently, homologues of sensor and response regulator genes were identified in Saccharomyces cerevisiae (Banuett, 1998). Since that observation was made, a systematic search for these genes has been performed on many other eukaryotic micro-organisms, including Candida albicans (Alex et al., 1998; Calera et al., 1998; Nagahashi et al., 1998).

Although bacterial histidine kinases are involved in the

The GenBank accession number for the CaHK1 sequence reported in this paper is AF013273. detection of many different stimuli (Hoch \& Silhavy, 1995), in eukaryotic micro-organisms the variety of environmental signals has been limited to osmolarity (Posas et al., 1996; Schuster et al., 1996; Shieh et al., 1997), oxidative stress (Morgan et al., 1997; Shieh et al., 1997), heat stress (Shieh et al., 1997) and nutritional limitations (Cottarel, 1997; Shieh et al., 1997). On the other hand, histidine kinases have been shown to play a key role in developmental processes of eukaryotic microorganisms. Thus, these proteins have been implicated in the morphogenesis of Dictyostelium discoideum and Neurospora crassa (Alex et al., 1996; Chang et al., 1998; Wang et al., 1996; Zinda \& Singleton, 1998). Finally, a link between environmental stress and growth in eukaryotic micro-organisms has also been established. Thus, in Schizosaccharomyces pombe, the Mcs4 response regulator has been reported to be an essential component of the Sty1 pathway, which coordinates the 
Table 1. Candida albicans strains used in this study

\begin{tabular}{|c|c|c|}
\hline Strain & Relevant genotype & Source/reference \\
\hline CAF2 & $\Delta u r a 3:: i m m 434 / U R A 3$ & Fonzi \& Irwin (1993) \\
\hline CAI4 & $\Delta u r a 3:: i m m 434 / \Delta u r a 3:: i m m 434$ & Fonzi \& Irwin (1993) \\
\hline CHK 11 & $\begin{array}{l}\Delta u r a 3:: i m m 434 / \Delta u r a 3:: i m m 434 \Delta c a b k 1:: \text { hisG-URA3- } \\
\text { hisG/CaHK1 }\end{array}$ & This work \\
\hline CHK 12 & $\Delta u r a 3:: i m m 434 / \Delta u r a 3:: i m m 434 \Delta c a b k 1:: b i s G / C a H K 1$ & This work \\
\hline CHK21 & 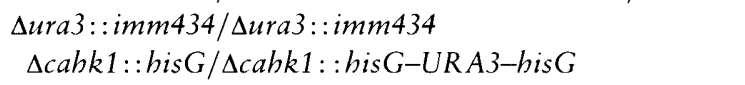 & This work \\
\hline CHK22 & 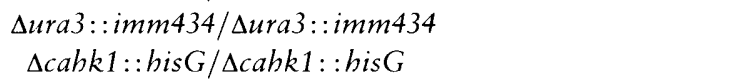 & This work \\
\hline CHK23 & 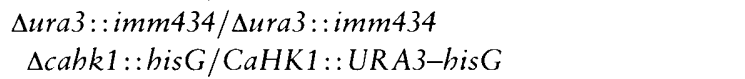 & This work \\
\hline
\end{tabular}

stress response with mitosis and meiosis (Cottarel, 1997; Shieh et al., 1997).

C. albicans, a polymorphic fungus of increasing medical importance, can grow as a yeast or form true hyphae and an intermediate pseudohyphal shape. In vitro, this morphological plasticity is regulated by a number of environmental signals, mainly $\mathrm{pH}$, temperature and medium composition. The yeast phase is favoured at $25^{\circ} \mathrm{C}$ and an acidic $\mathrm{pH}$; hyphal growth is favoured at $37^{\circ} \mathrm{C}$ and a $\mathrm{pH}$ near neutrality. Medium composition, particularly the presence of serum or other inducing compounds, can favour growth as hyphae. The factors responsible for the virulence of $C$. albicans are still not well understood, but pseudohyphae/hyphae exhibit increased adherence to host tissues and increased invasiveness (Chaffin et al., 1998). Several hyphal-cellwall moieties mediate the interaction between the fungal cell and the host, and contribute to the initiation of the pathogenic process, including cell-wall proteins and mannoproteins which are the major mediators of adhesion. During the past several years, many candidal adhesins and host ligands that mediate the adherence of C. albicans have been characterized; most of the adhesins that have been detected are associated with the cell wall of germ tubes (for a detailed review see Chaffin et al., 1998). However, few adhesins have been characterized at the molecular level, and although the expression of many of these components seems to be environmentally regulated, no information is available about the mechanisms that regulate their expression. Recently, Als1p (agglutinin-like sequence) has been identified as a putative candidal adhesin ( $\mathrm{Fu}$ et al., 1998a). Also, a relationship between flocculation and adherence was suggested since the expression of the CAD1/AAF1 from C. albicans in $S$. cerevisiae causes cells to flocculate and exhibit enhanced adherence to endothelial cells (Fu et al., 1998b). Again, the relationship of cell-surface-adhesin expression and signal pathways is unknown.

To identify genes of environmentally regulated pathways, a search for histidine kinase homologues of $C$. albicans has also been performed and three putative histidine kinase genes, CaHK1, CaSLN1 and CaNIK1/COS1, have been described thus far (Alex et al., 1998; Calera et al., 1998; Nagahashi et al., 1998). CaSLN1 and CaNIK1/COS1 are the homologues of SLN1 from Sacch. cerevisiae and nik-1 $1^{+}$from N. crassa, which are involved in osmoregulation and morphogenesis, respectively (Alex et al., 1998; Nagahashi et al., 1998). However, the structural homology that is found between Cahk1p and other histidine kinases is restricted to its C-terminal domain, in which the key histidine and aspartyl domains involved in phosphotransfer are located. The histidine kinases that are most likely to be related to Cahk $1 \mathrm{p}$, both structurally and perhaps also functionally, are two putative sensor kinases from Schiz. pombe (GenBank accession nos Z98978 and AL031543). These are the only histidine kinases in which the $\mathrm{N}$ terminal domains show similarity with the N-terminal domain of Cahk1p. However, the role of these sensor histidine kinases in Schiz. pombe is unknown, and no function for Cahk1p can be inferred from their similarity. In this paper we describe the construction of a $\Delta c a b k 1$ null strain and its phenotype. Our data are indicative of a role for Cahk $1 \mathrm{p}$ in regulating the expression of hyphal cell surface component(s).

\section{METHODS}

Strains and growth conditions. The C. albicans strains used in this work are listed in Table 1 . All strains were routinely grown either in YPD complex medium (1\% yeast extract, $2 \%$ peptone and $2 \%$ glucose) or YNB minimal medium $[0.67 \%$ yeast nitrogen base (Gibco-BRL), $2 \%$ glucose] at $28^{\circ} \mathrm{C}$ for 14-16 h. Cells were harvested from liquid medium by centrifugation at $4000 \mathrm{~g}$ for $10 \mathrm{~min}$ at $4{ }^{\circ} \mathrm{C}$. For specific experiments, strains were also grown in YED ( $1 \%$ yeast extract, $2 \%$ glucose) with the $\mathrm{pH}$ adjusted either to $\mathrm{pH} 3.5$ or 7.5 , or in medium 199 containing Earle's salts and glutamine but lacking sodium bicarbonate (Gibco-BRL) and buffered with $155 \mathrm{mM}$ Tris/ $\mathrm{HCl}$ either at $\mathrm{pH} 7.5$ or 3.5 . These media were also supplemented with either $1 \mathrm{M}$ sorbitol or $1.5 \mathrm{M} \mathrm{NaCl}$. Cultures were inoculated to a density of $10^{7}$ cells $\mathrm{ml}^{-1}$ into prewarmed medium and incubated either at $28^{\circ} \mathrm{C}$ or $37^{\circ} \mathrm{C}$ with vigorous agitation. In all cases, stationary-phase cells grown at $28^{\circ} \mathrm{C}$ in YPD were used as the inoculum. Uridine was added to a final concentration of $25 \mu \mathrm{g} \mathrm{ml}{ }^{-1}$ when necessary. 
(a)
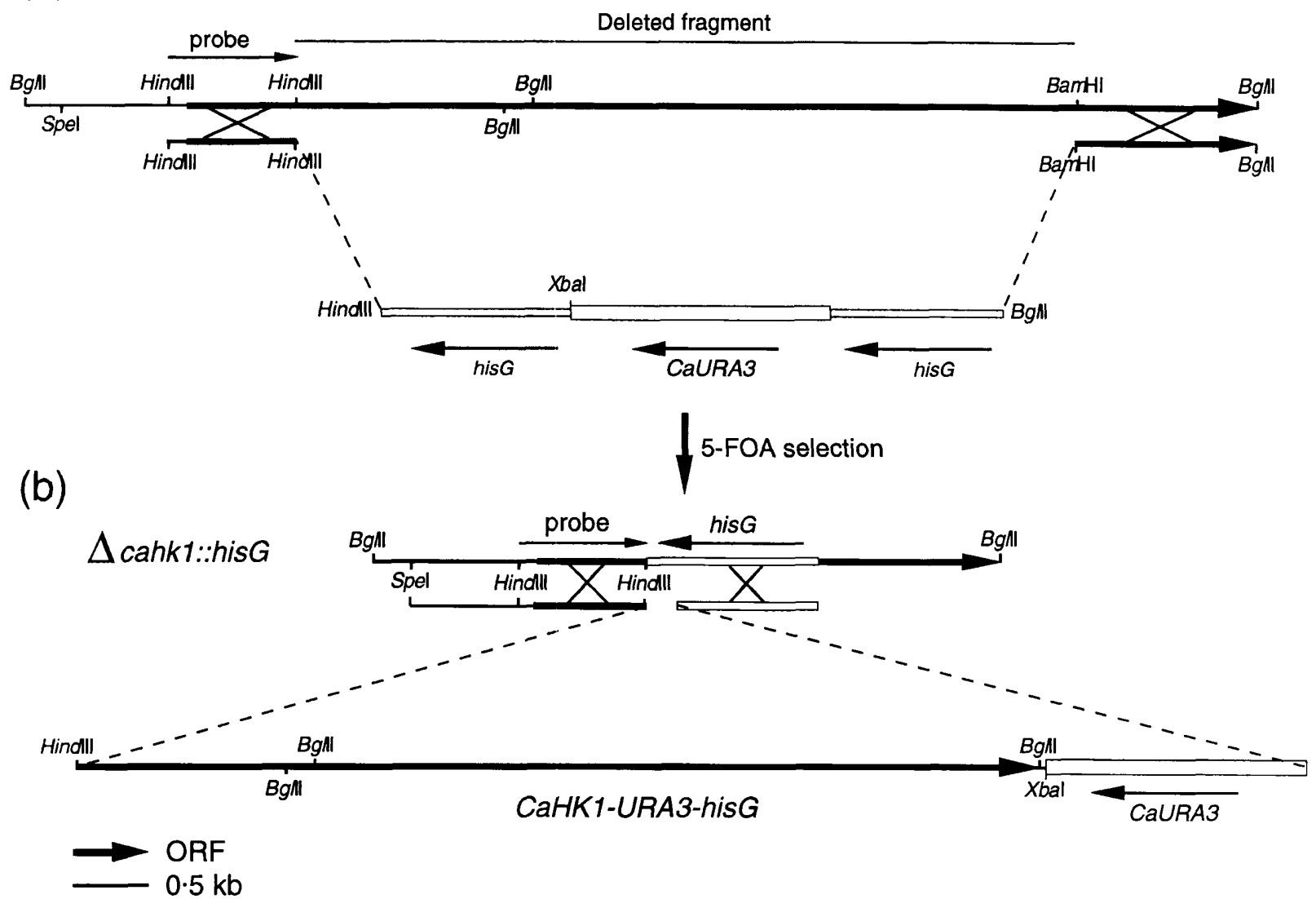

(c)

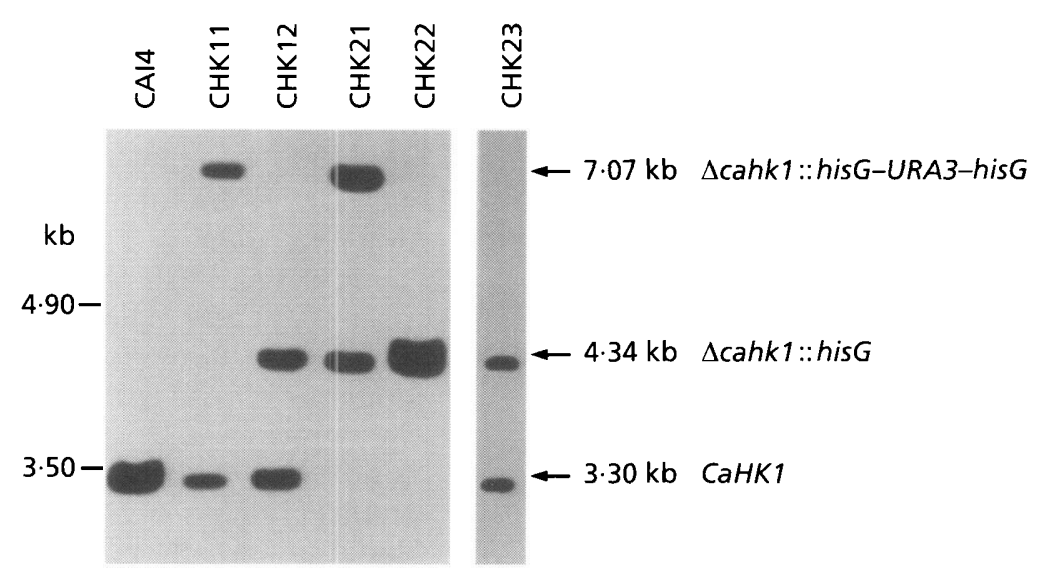

Fig. 1. (a) Schematic representation of the construction of the cassette used to disrupt CaHK1 and (b) the CaHK1-URA3-hisG cassette used to reintroduce one wild-type CaHK1 allele. (c) The corresponding Southern-blot analysis of representative $\Delta c a h k 1$ mutants obtained during the disruption process, and one revertant strain (CHK23). Genomic DNA from these strains was $B g / l$ digested, and hybridized with a $0.89 \mathrm{~kb}$ fragment located at the $5^{\prime}$ end of the CaHK1 gene as a probe. The exact size and genotype of the expected hybridizing DNA fragments are indicated on the right.

Escherichia coli strain $\mathrm{DH} 5 \alpha$, which was used for transformation and plasmid amplification, was grown at $37^{\circ} \mathrm{C}$ in LB broth supplemented with $0 \cdot 1 \mathrm{mg}$ ampicillin $\mathrm{ml}^{-1}$ when necessary.
DNA manipulations. E. coli was routinely transformed by standard methods (Sambrook et al., 1989). Plasmid DNA was extracted from E. coli DH5 $\alpha$ cells using the Plasmid Midi Kit according to the manufacturer's instructions (Qiagen). Re- 
striction enzymes and T4 DNA ligase were obtained from Gibco-BRL and used with buffers provided by the supplier under the recommended conditions. Agarose gel electrophoresis of both DNA and RNA was performed according to standard protocols (Sambrook et al., 1989). Construction of recombinant plasmids and selection of transformants were done by standard techniques (Sambrook et al., 1989).

Southern- and Northern-blot analyses. Genomic DNA from all C. albicans strains was obtained according to the method described by Sherman et al. (1986). Four micrograms of DNA per lane was typically loaded for Southern analyses. DNA was transferred by capillarity to positively charged nylon membranes (Hybond-N+; Amersham) by standard protocols (Sambrook et al., 1989). All probes used for Southern blots were digoxigenin labelled by random priming (DIG DNA Labelling Kit; Boehringer Mannheim), and hybridized and detected according to the chemiluminescent method described in the manufacturer's recommendations (DIG Nucleic Acid Detection Kit; Boehringer Mannheim).

Total RNA was isolated according to the protocol described by Sherman et al. (1986). Fifteen micrograms of total RNA per lane was loaded onto $1 \%(\mathrm{w} / \mathrm{v})$ formaldehyde agarose gels and transferred by capillarity to nylon membranes (Hybond$\mathrm{N}$; Amersham) using $20 \times$ SSC, according to standard protocols (Sambrook et al., 1989). The probes used for hybridization of Northern blots were labelled by random priming using the DNA Labelling Beads (-dCTP) kit and $[\alpha-$ $\left.{ }^{32} \mathrm{P}\right] \mathrm{CTP}$ (Pharmacia Biotech). A probe for the C. albicans actin gene was used as a control for equal loading. Hybridization was carried out at $68^{\circ} \mathrm{C}$ in a solution containing $0.5 \mathrm{M} \mathrm{NaH}_{2} \mathrm{PO}_{4}$ (pH 7.2), $7 \%$ SDS and $1 \mathrm{mM}$ EDTA. After hybridization, the blots were washed twice with $2 \times$ SSC containing $0.2 \%$ SDS at $68^{\circ} \mathrm{C}$ for $20 \mathrm{~min}$. The $0.24-9.5 \mathrm{~kb}$ RNA ladder (Gibco-BRL) was used for sizing in formaldehyde agarose gels.

PFGE. Chromosomal DNA was resolved by PFGE according to the protocol described by Wickes et al. (1991), in a Bio-Rad CHEF DRII unit with a linear ramp switch time of 300-1400 s for $144 \mathrm{~h}$ at $13{ }^{\circ} \mathrm{C}$. Gels were stained for $30 \mathrm{~min}$ with ethidium bromide $\left(0.5 \mu \mathrm{g} \mathrm{ml}^{-1}\right.$ in water), destained in distilled water for $30 \mathrm{~min}$ and then photographed. The gels were blotted onto nylon membranes by alkaline transfer for $16 \mathrm{~h}$. The probe used was radioactively labelled by random priming and hybridized as described above.

Isolation of the CaHK1 gene. CaHK1 was isolated and subcloned into three different fragments which overlapped, as previously described (Calera et al., 1998). However, for further studies, an $8.4 \mathrm{~kb}$ SpeI-NheI DNA fragment which contains the entire ORF of CaHK1, was subcloned into the SpeI/XbaI restriction sites of $\mathrm{pBSK}+$ (Strategene) and used to construct the CaHK1-URA3-hisG cassette.

Construction of the vectors used in disruption and reconstitution experiments of CaHK1. To obtain $\Delta c a b k 1$ mutants, the pMB73 vector, which carries a cassette designed to delete most of the ORF of CaHK1, was constructed. A $1 \cdot 25 \mathrm{~kb} \mathrm{BamHI-BglII}$ fragment, that includes the $3^{\prime}$ end of CaHK1, was ligated to the only BglII site that flanks the $5^{\prime}$ end of the his G-URA3-his G cassette in the pMB7 vector (Fonzi \& Irwin, 1993), to generate pMB71. To complete the construction of pMB73, a $0.89 \mathrm{~kb}$ HindIII fragment located in the $5^{\prime}$ end of CaHK1, 5.42 kb upstream from the $1.25 \mathrm{~kb}$ BamHI$B g l l l$ fragment, was introduced in the appropriate orientation into the HindIII site that flanks the $3^{\prime}$ end of the pMB71 cassette to generate pMB73 (Fig. 1a). The pMB73 plasmid was linearized by digestion with SacI which cuts once in the plasmid outside of the cassette. Approximately $15 \mu \mathrm{g}$ trans- forming DNA was used to transform the $\mathrm{Ura}^{-} \mathrm{C}$. albicans strain CAI4 according to the method described by Gietz et al. (1991). Transformed cells were selected as $\mathrm{Ura}^{+}$on YNB minimal medium. One spontaneous $\mathrm{Ura}^{-}$derivate from a $\mathrm{Ura}^{+}$ independent clone was selected on YNB medium containing $5^{\prime}$-fluoroorotic acid (5'-FOA) and uridine, and used to delete the second allele of CaHK1. The disruption-transformation was repeated to generate a null mutant, and both pre- and post-5-FOA isolates were verified by Southern blot analyses. To obtain a reconstituted strain in one of the alleles, a $\Delta c a b k 1$ null strain was transformed with the CaHK1-URA3-hisG cassette as shown in Fig. 1(b).

\section{RESULTS}

\section{Structural features of the N-terminus of Cahk1p}

As we have previously reported, CaHK1 encodes a 2471 aa hybrid histidine kinase (Cahk1p) whose Cterminal domain shows a strong homology with both the histidine and aspartyl domains from several bacterial and fungal histidine kinases (Calera et al., 1998). The Nterminal domains of sensor histidine kinases are involved in the detection of specific environmental signals, and their primary structure determines the kind of stimuli they sense (Parkinson, 1993). In this regard the CaSln $1 \mathrm{p}$ and CaNik1p histidine kinases from $C$. albicans, which show a high homology in their $\mathrm{N}$ terminal domains with the proteins $\operatorname{Sln} 1 \mathrm{p}$ from $S$. cerevisiae and Nik-1 from N. crassa which are involved in osmoregulation and morphogenesis, respectively, were reported to function similarly in C. albicans (Alex et al., 1998; Nagahashi et al., 1998). For this reason, we searched for similarities to the N-terminal domain of Cahk1p with other proteins in the databases, to predict the potential stimuli it could sense. This search revealed significant homology of the Cahk1p N-terminal domain with the putative PknB Ser/Thr kinase from Mycobacterium tuberculosis (GenBank accession no. Z80233) and less homology (but still significant) with the calcium/calmodulin-dependent kinases type I from different species. This homology lies between amino acids 463 and 640 of Cahk1p and 112 and 278 of $\mathrm{PknB}$ from $M$. tuberculosis $(31.5 \%$ identity and $49.4 \%$ similarity). However, this homology is restricted to domains VIa-XI of PknB and other Ser/Thr kinases (Fig. 2a), which have been described to be largely responsible for binding of peptide substrates and initiating phosphotransfer (Hanks \& Hunter, 1995). A P-loop motif, which could potentially be involved in ATP or GTP binding (Saraste et al., 1990), was also found between amino acids 718 and 724 of Cahk1p, downstream of the homologous Ser/Thr-kinase XI-domain (Fig. 2b). On the other hand, from a recent search against the nonredundant database using the BLASTP program (Altschul et al., 1990), we found a putative 2310 aa sensor histidine kinase from $S$. pombe which shows significant homology with Cahk1p (GenBank accession no. Z98978, hereafter called Sphk1 for $S$. pombe histidine kinase; the name given by the genome sequencing project is SPAC27E2.09). In addition to the similarity of the Cterminus of Sphk1 with the Cahk1p C-terminus, in which the histidine and aspartyl domains are located, 
(a)

Cahk1P 463 PMKLIEILTDIMRVVET ISVIHELGFVENGLTSSNLLKSEKNVRDIKITGWGFAFSFTENCSQGYRNKHLAQVQDLI PYMAPEVLAITN 551 PknB $112 \mathrm{P}+\mathrm{IE}++\mathrm{D}+++\mathrm{B}+\mathrm{G}+\mathrm{H}++\mathrm{N}++\mathbf{S} \mathrm{N}+\mathrm{K}++\mathbf{G} \mathrm{A}+++\quad \mathrm{G}$ A V $\mathrm{Y}++\mathbf{P E}$ 112 PKRAIEVIAD---ACQALNFSHQNGIIMRDVKPANIMISATNA--VKVMDFGIARAIADS---GNSVTPTAAVIGTAQYLSPE--QARG 190

Cahk1p 552 SVVDYRSDFYSLGVIMYELVLGILPTKNSNPOKLIRMHTFENPIAPSALAPGWISEKLSGVIMKLLEKHPHNRYTDCHSLLHDLIEVKN 640 PknB $19 D$ RSD YSLG ++YE++ G PF +P + H E+PI PSA G +S L V++K L K+P NRY $+\mathrm{DL}+\mathrm{V} \mathrm{N}$ PknB 191 PSVDARSDVYSLGCVLYEVLTGEPPFrGDSPVSVAYQHVREDPIPPSARHEG-LSADLDAVVLKALAKNPENRYQTAAEMRADLVRVHN 278 IX

$\mathrm{x}$

$\mathrm{XI}$

(b)

Sphk1 90 LLLNETLGALIYD-DPGPNILD--EWLGNPNPLDLKLFLKFALGVSYVLCFLHEKKIVHGEIRLDTFHYDLNAPIHAKLLTIGSSVSPI 175

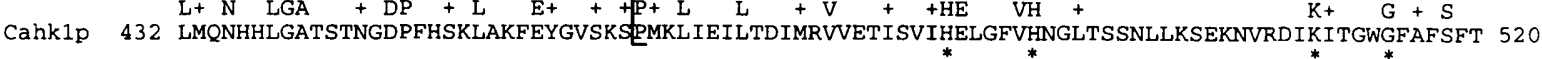
Sphk1 176 RFTLSSLNWKRLYQVQNICHKLQFFSPEQIGNVGR PLDSRSDIYSLGILFYVILTKQYPWGGQSMRIVQSIHMRQFPSVLPRRPDAF-- 262

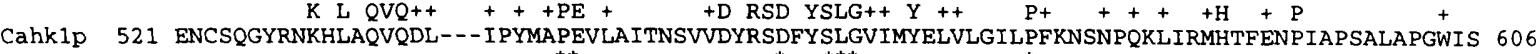
Sphk1 263 PALDQLIQKMTAKSMNSRISSATDLCYTIVELMÖEF--STITSSPLLDQKLLSINKPQQEKLLKFPKLLLTNSSDYVRIFHELVAFSSKR 349

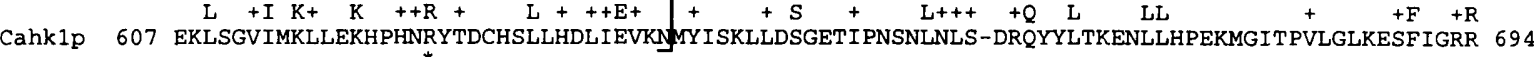

Sphk1 350 DLLTSAKRVDKLPKQHLFKYRPVDNEATYCQVVTVIGEKGSGKSNL---LNAVADEARKFGYFAMSSFKGHHFSPYSAIFKCVSLIMQQ 435 Cahk1p $695 \mathrm{DL}+\mathrm{V}+\mathrm{N}+\mathrm{N}++\mathrm{GEG} \mathrm{GK+}+\mathrm{LAA}+\mathrm{FY} \mathrm{SFG} \mathrm{Y}++\mathrm{V} \mathrm{I}+\mathrm{Q}$ Cahk1p 695 DFLQNVTEV----.-.-.-.-YNNSKNG IDLLF I SGESGRGKTI ILQDLRAAAVLKQDFYYSWKFSFFGADTHVYRFLVEGVQKI ITQ 770 P-10op

Sphk1 436 TLREEKQLVTDYFTSLWEFLGFQLIYMGELFEYVPELNSLL 476

Cahk1p 771 ILNSSEEIQNTWRDVILTHIPIDL---SILFYLIPELKVLL 808

(c)

Sphk2 121 NPA---EFVRFCIAICKCIEYLHSKGMVHGEIRLDSFIPISSYDNVYMLTV---GSGASYFHNCLQAHNWRKYSEDSESMSRILFISPE 203

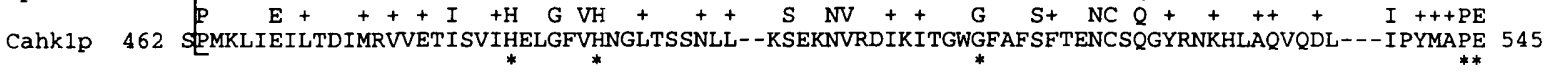
Spkh2 204 QTGRTSYSVGYRTDIYSLGVLFFHYLSDCSPYTGSFVQRIRSILT--EPLPDISKSCPKLPHLIFKIIEKMTRKNPDERYTSCSGIVND 290 T+ V YR+D YSLGV $++\mathrm{P}_{+} \mathrm{S} \mathrm{Q}+++\mathrm{T} \mathrm{P}+++++++\mathrm{I} \mathrm{K}_{+} \mathrm{K}+\mathrm{P} \mathrm{RYT} \mathrm{C}+++\mathrm{D}$ Cahk1p 546 VLAITNSVVDYRSDFYSLGVIMYELVLGILPFKNSNPQKLIRMHTFENPIAPSALAPGWISEKLSGVIMKLLEKHPHNRYTDCHSLLHD 634

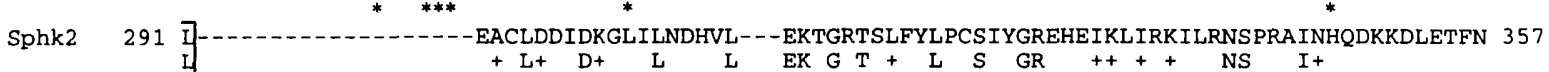

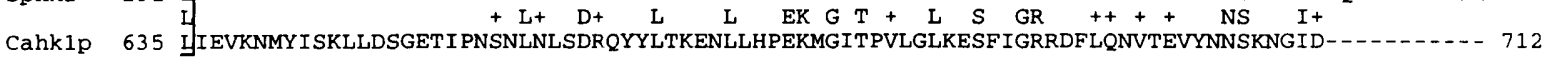
Sphk2 358 PYYLNAIESESSSQSLSLSQRASEVMPLVILITGCEGIGESSLIQTI---CDRREGYMAITKFEV--SQSIVYSAIVSAVAEFIRQILA 441 Sphk2 358 PYYLNAIESESSSQSLSLSRASEVMP $+\mathrm{I}+\mathrm{G}+\mathrm{GG}+++\mathrm{Q}+2+++\mathrm{KF}++\mathrm{VY}+\mathrm{V} \mathrm{V}+\mathrm{I} Q \mathrm{QIL}$ Cahk1p 713 -

Sphk2 442 EDQLLLNNFFEELKNKLESDLYLLDSVFDLVPEIRSLL 479

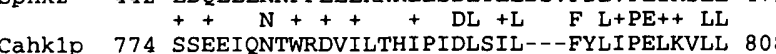

(d)

Sphk1

Sphk2

Cahk1p

CaSIn $1 p$

CaNik1p

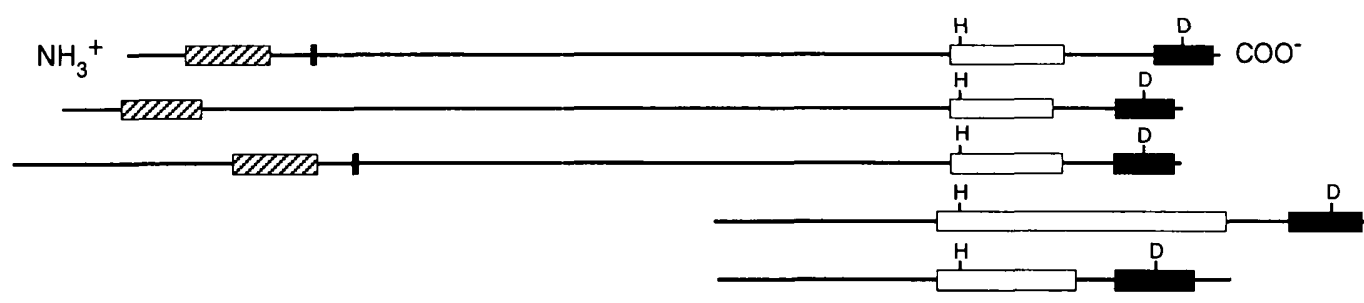

Fig. 2. (a) Comparison of Cahk $1 \mathrm{p}$ and the putative PknB Ser/Thr kinase from $M$. tuberculosis. Only the Vla-XI domains of PknB, which have homology with Cahk1p, are shown. The conserved residues in all Ser/Thr kinases are indicated with an asterisk, and those residues also conserved in Cahk $1 p$ are shown in bold and indicated by bold asteriks. (b, c) Comparison of the N-terminal domains of Cahk $1 \mathrm{p}$ and Sphk1 (b) and the N-terminus of Cahk1p and Sphk2 (c). The exact location of the homologous Ser/Thr-kinase domains are bracketed, and the conserved P-loop motifs are boxed. The asteriks indicate those residues conserved in all of the Ser/Thr kinases. (d) Comparison of the $C$. albicans histidine kinases (Cahk1p, CaSln1p and CaNik1p) with the putative sensor kinases from S. pombe (Sphk1 and Sphk2). In Cahk1p, Sphk1 and Sphk2, the positions of the Ser/Thr-homologous domains (hatched boxes), and the adjacent P-loop motifs in Cahk1p and Sphk1 (small black boxes) are shown. Also the histidine (white boxes) and the aspartyl domains (large black box) of these proteins, and from CaSln $1 p$ and CaNik $1 p$ are indicated. The proteins were aligned with the putative autophosphorylated histidine residue as a reference point. 
also the same structural features in their N-terminal domains were observed, including the homologous Ser/Thr-kinase domains and the P-loop motif $(20.7 \%$ identity, $40.0 \%$ similarity) (Fig. 2b). In addition, we have recently found a second putative 2344 aa histidine kinase from $S$. pombe which also exhibits similarity with both the $\mathrm{N}$ - and C-termini of Cahk1p [GenBank accession no. AL031543, hereafter called Sphk2; the name given by the genome sequencing project is SPCC74.06]. The homology between the N-terminal domains of Cahk1p and Sphk2 was restricted to their Ser/Thr-kinase domains ( $24.1 \%$ identity, $46.0 \%$ similarity) (Fig. 2c). However, contrary to Sphk1 and Cahk1p, Sphk2 does not have a P-loop motif. Also, in these putative sensor kinases from $S$. pombe, the Ser/Thr-kinase domains and the P-loop (in Sphk1) are arranged in the same relative positions as in Cahk1p (Fig. 2d). Thus, in Cahk1p and Sphk1, the conserved arginine residues in the $\mathrm{Ser} / \mathrm{Thr}$ homologous XI domains are separated from their corresponding P-loops by 94 and 106 aa respectively, and the P-loops from Cahk1p and Sphk1 are separated from the corresponding putative autophosphorylated histidine residues by 1289 and 1395 aa, respectively. Similarly, the conserved arginine residue in the Ser/Thr homologous XI-domain of Sphk2 is separated from its corresponding putative autophosphorylated histidine residues by $1515 \mathrm{aa}$.

\section{Construction of a CaHK1 null mutant}

To characterize the function of CaHK1 in the growth and morphogenesis of $C$. albicans, we used the urablaster technique (Fonzi \& Irwin, 1993) for obtaining a $\Delta$ cahk1 null mutant. We also constructed a strain reconstituted for one allele to ensure that the resulting phenotype was not due to extraneous mutations that could happen during transformation. Thus, we used a cassette (see Methods) to replace a $5.42 \mathrm{~kb}$ fragment of CaHK1 which includes the coding regions for the conserved Ser/Thr-kinase domains, the P-loop motif and putative autophosphorylated histidine (Fig. 1a). After the first round of transformation, $\mathrm{Ura}^{+}$transformants were selected on YNB minimal medium and 15 isolates were tested by Southern blotting to confirm this replacement. The results showed that all transformants had incorporated the his $G-U R A 3-b i s G$ cassette in the predicted site. DNA from a representative isolate (strain CHK11) exhibited two CaHK1 hybridizing bands: a $3.3 \mathrm{~kb} \mathrm{Bg} / \mathrm{II}$ fragment characteristic of the parental strain and an additional fragment of $7.07 \mathrm{~kb}$, consistent with the replacement in one allele of CaHK1 with the his $G-$ URA3-his G cassette (Fig. 1c). Ura ${ }^{-}$segregants of strain CHK11 were selected on $5^{\prime}$-FOA plates and examined by Southern blotting. Strain CHK11 is a representative intrachromosomal recombinant (Fig. 1c). The $7 \cdot 07 \mathrm{~kb}$ $B g l$ II fragment seen in strain CHK11 which had contained the $\Delta c a b k 1:$ :hisG-URA3-hisG disruption was absent in CHK12, and a new $4.34 \mathrm{~kb}$ hybridizing fragment was present. The size of this fragment is consistent with the desired event, loss of URA3 and one copy of hisG. Following the same protocol, a second

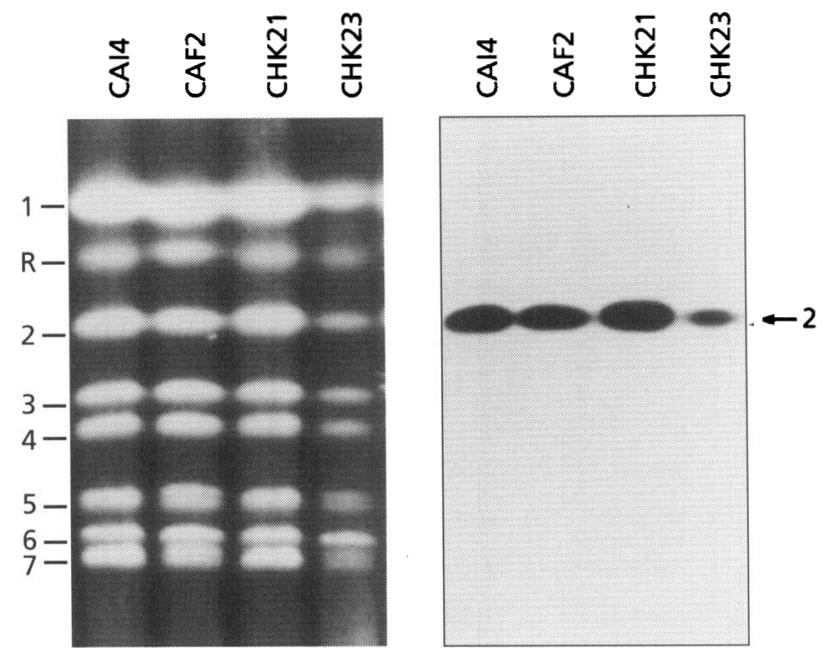

Fig. 3. CHEF gel analysis of the $\triangle$ cahk1 null (CHK21) and revertant (CHK23) strains. CAI4 and CAF2 were used as controls. The chromosome bands were visualized by ethidium bromide staining (left panel), transferred to a nylon membrane and probed with a $0.89 \mathrm{~kb}$ fragment located at the $5^{\prime}$ end of the CaHK1 gene as a probe (right panel). A hybridizing band corresponding to chomosome 2 was detected. The chromosomal designations are indicated on the left, according to Wickes et al. (1991).

round of transformation was performed and the remaining allele was disrupted. In Fig. 1(c) a representative $\mathrm{Ura}^{+}$isolate (strain CHK21) and a $\mathrm{Ura}^{-}$segregant (strain CHK22) are shown. A strain reconstituted for one allele was constructed after transformation of CHK22 with the CaHK1-URA3-hisG cassette. This cassette allowed the integration event to occur between the remaining $5^{\prime}$ end of $\mathrm{CaHK} 1$ and the his $G$ that had replaced $5.42 \mathrm{~kb}$ of the CaHK1 sequence in CHK22 (Fig. 1b). Ura ${ }^{+}$transformants were selected on YNB medium, and the integration of the transforming DNA in the $\Delta c a b k 1$ :: his G locus was verified by Southern-blot analysis from several isolates. Southern-blot analysis of one representative isolate (CHK23) is shown in Fig. 1(c). The $3.3 \mathrm{~kb} \mathrm{BgllI}$ fragment that was detected is consistent with the replacement of one disrupted allele ( $\triangle$ cabk1:: hisG) of the CHK22 strain with the CaHK1URA3-his G cassette, restoring one CaHK1 allele.

\section{Chromosomal location of CaHK1}

To show that in the null and revertant strains, the CaHK1 locus had not undergone extraneous chromosomal rearrangements during their manipulation, chromosomes from these and the control strains CAF2 and CAI4 were separated by PFGE and probed with a $0.89 \mathrm{~kb}$ HindIII fragment from the $5^{\prime}$ end of CaHK1. Results showed that CaHK1 is located on chromosome 2 in the four strains (Fig. 3). Further, additional sequencing of the $3^{\prime}$ end of $\mathrm{CaHK} 1$ also contributed to the mapping studies, in that the stop codon of CaHK1 is located only $136 \mathrm{bp}$ from the stop codon of the CaHOG1 gene, which also is located on chromosome 2 (San Jose et al., 1996). 


\section{Phenotypic analysis of the $\Delta$ cahk1 mutants}

The effect of the CaHK1 deletion on the phenotype of the $\Delta c a b k 1$ mutants was studied under conditions that promote both yeast and hyphal growth in C. albicans. Thus, the Ura ${ }^{+} \Delta$ cabk1 mutants (CHK11 and CHK21) and the control strain (CAF2) were grown in a rich medium ( $\mathrm{YED}$ at $\mathrm{pH} 3.5$ and $\mathrm{pH} 7.5$ ) and a synthetic medium (medium 199 at $\mathrm{pH} 3.5$ and $\mathrm{pH} 7.5$ ) at $28^{\circ} \mathrm{C}$ and $37^{\circ} \mathrm{C}$. Also, because many of the eukaryotic histidine kinases act as osmosensors, each medium was supplemented with $1.5 \mathrm{M} \mathrm{NaCl}$ or $1 \mathrm{M}$ sorbitol to determine if CaHK1 was also involved in osmoregulation. In both liquid media at $\mathrm{pH} 3.5$, we observed that the disrupted strains grew like CAF2 but at $\mathrm{pH} 7 \cdot 5$ the disrupted strains showed extensive aggregation that we defined as a flocculation-like phenotype (Fig. 4a). The flocculation was more dramatic in medium 199 at $\mathrm{pH} 7.5$ than in complex media at the same $\mathrm{pH}$. In addition, flocculation was more extensive in the null strain than in the single-allele-disrupted strain, indicating a gene-dosage-dependent phenotype (Fig. 4a). Also, it was observed that flocculation of CHK21 was much less extensive in the presence of osmostressing agents and under these conditions of growth the appearance of the culture in liquid media was similar to that of CAF2 at $\mathrm{pH} 7.5$ (Fig. 4a).

Using medium 199 to perform further analysis of this phenotype, it was observed that at $28^{\circ} \mathrm{C}$ the flocculation became apparent in the null strain after $3 \mathrm{~h}$ culture but only after $4 \mathrm{~h}$ did the flocculation became obvious in the heterozygote. The same phenomenon was observed at $37^{\circ} \mathrm{C}$ but flocculation became apparent earlier in both the null and heterozygote strains. Thus, it seems that temperature has no effect on the phenotype except to accelerate the flocculation process, most likely as a consequence of faster growth of the cells at $37^{\circ} \mathrm{C}$. These dramatic changes in the growth of the disruptants were not observed in the control strain CAF2. Microscopic observations were consistent with the macroscopic appearance of liquid cultures from CAF2 and the CHK21 $\Delta$ cabk1 null strain. Thus, CHK21 formed germ tubes at $\mathrm{pH} 7.5$ at the same rate as CAF2 (after $1.5 \mathrm{~h}$, $100 \%$ of the cells have formed germ tubes in CAF2 and CHK21), but CHK21 formed larger aggregates that rapidly sedimented (Fig. 4a). A microscopic study (Fig. 4b) demonstrated that, even though germ-tube formation in CHK21 occurred as fast as in CAF2 (Fig. 4b, bottom left panel), flocculation in the $\Delta c a b k 1$ null strain primarily occurs through interactions along the hyphal surface which become clustered in stacks (Fig. 4b, bottom right panel). However, at $\mathrm{pH} 3 \cdot 5$ the $\Delta$ cabk1 null strain, as well as CAF2 (Fig. 4b, top left panel), grew as yeasts but the CHK21 cells showed a more elongated shape (Fig. 4b, top right panel).

On the other hand, to understand the effect of osmostressing agents on flocculation we considered that increased osmolyte concentration inhibits hyphal development in a wild-type strain of C. albicans as previously reported (Alex et al., 1998). However, the (a)

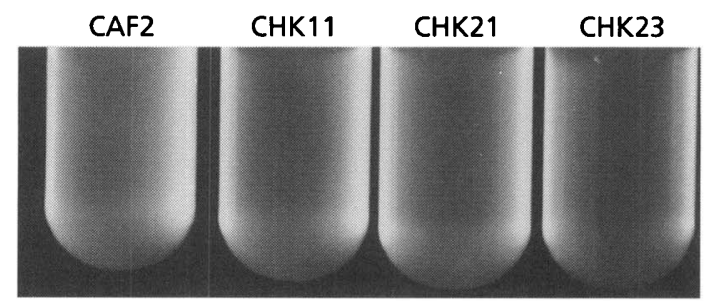

$\mathrm{pH} 3 \cdot 5$

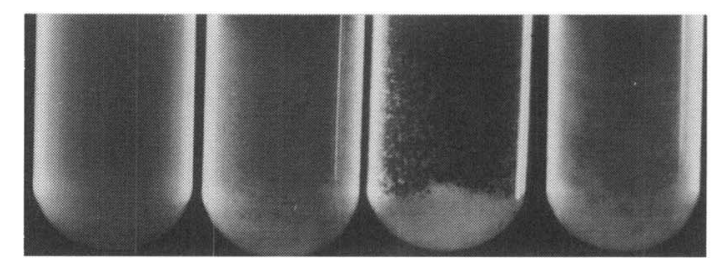

(b)
CAF2

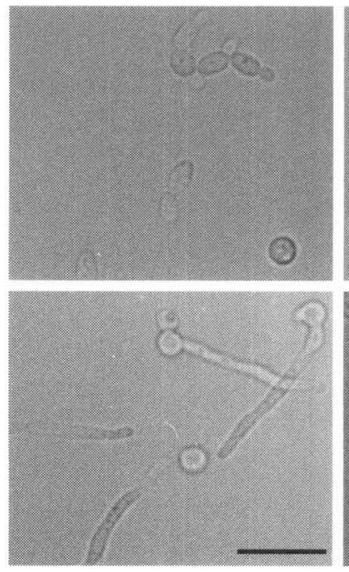

CHK21

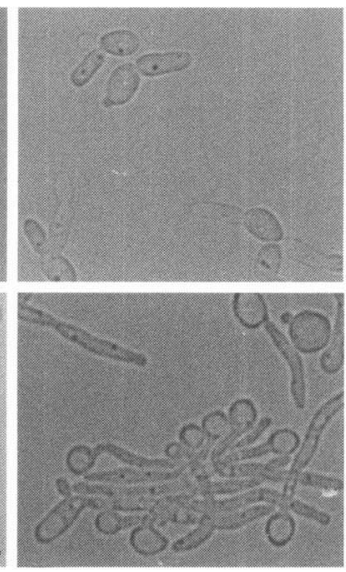

Fig. 4. (a) Broth cultures of both Ura ${ }^{+} \Delta c a h k 1$ mutants (CHK11 and CHK21) and revertant strain CHK23. Stationary-phase cells from all strains were inoculated $\left(10^{7}\right.$ cells $\left.\mathrm{ml}^{-1}\right)$ in medium 199 at either $\mathrm{pH} 3.5$ or $\mathrm{pH} 7.5$, grown at $37^{\circ} \mathrm{C}$ for $3 \mathrm{~h}$ and photographed. Only at $\mathrm{pH} 7.5$ did the null strain flocculate, forming clumps of cells that sedimented rapidly after the cell suspension was shaken. Also, in the heterozygotes some flocculation is observed at pH 7.5. (b) Microscopic observations of CAF2 and the $\Delta c a h k 1$ null strain (CHK21) grown in medium 199 at pH 3.5 (top panels) and pH 7.5 (bottom panels) for $3 \mathrm{~h}$ at $37^{\circ} \mathrm{C}$. Flocculation occurs by an intimate interaction of hyphae along their surface forming stacks of germinated cells (bottom right panel). Bar, $6 \mu \mathrm{m}$.

osmolyte concentrations that we have used $(1.5 \mathrm{M} \mathrm{NaCl}$ and $1 \mathrm{M}$ sorbitol) did not alter the rate of germination of CAF2 and CHK21 compared to cells grown in absence of osmostressing agents $(100 \%$ germination after $1.5 \mathrm{~h}$ in both), but did retard the elongation of hyphae in both strains. In fact, the elongation of the germ tubes of CHK21 was more retarded by osmostressing agents than CAF2 (after 1.5 h the length of the germ tubes from CHK21 was half that of CAF2). Thus, this is consistent with the reduced flocculation of the $\Delta c a b k 1$ null strain observed in medium 199 ( $\mathrm{pH} 7.5$ ) supplemented with $1.5 \mathrm{M} \mathrm{NaCl}$ or $1 \mathrm{M}$ sorbitol. Since flocculation occurs primarily along the entire length of the hyphal surface, the reduced elongation of germ tubes in presence of 
$\mathrm{pH} 3 \cdot 5$

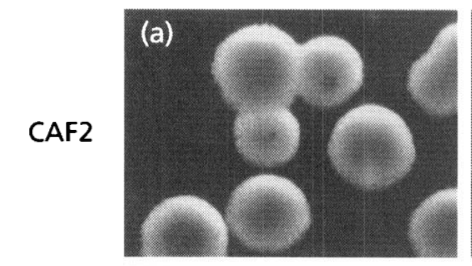

CAF2
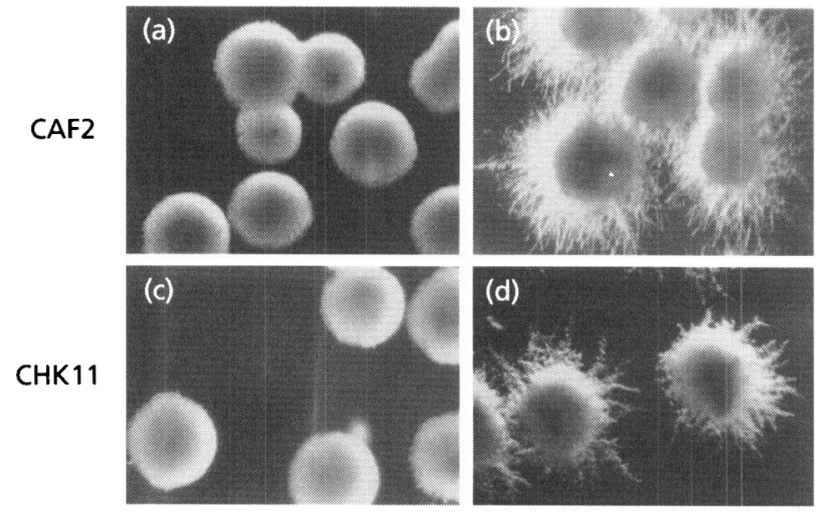

CHK21
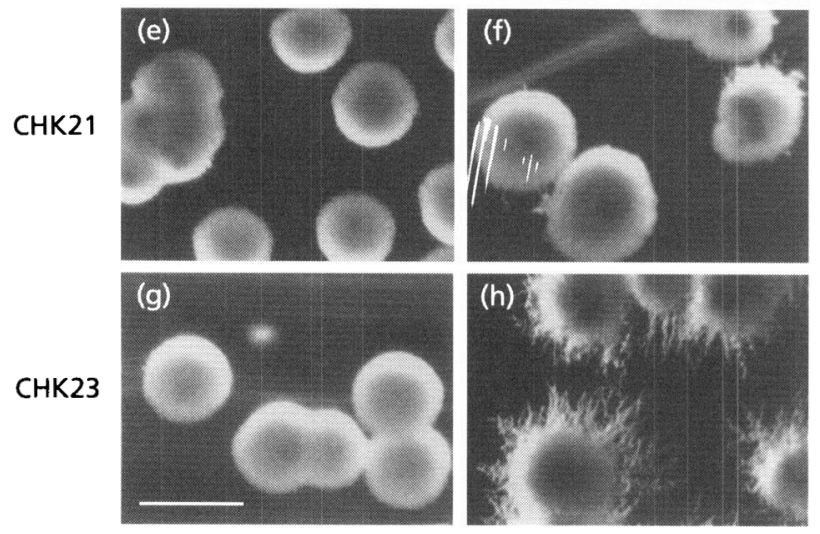

Fig. 5. Colony phenotype of the $\Delta$ cahk 1 mutants (CHK11 and CHK21). The CAF2 and CHK23 strains were included as controls. All strains were grown on medium 199 agar at either $\mathrm{pH} 3.5$, $28{ }^{\circ} \mathrm{C}$ or $\mathrm{pH} 7.5,37^{\circ} \mathrm{C}$ for $4 \mathrm{~d}$. At $\mathrm{pH} 3.5$, all strains grew like yeasts and formed smooth colonies, including the $\Delta$ cahk 1 mutants (c, e). At pH 7.5 the CHK11 (heterozygote, panel d) and CHK23 (revertant, panel h) formed less fuzzy colonies in comparison to CAF2 (b). However, the $\Delta$ cahk1 null strain (CHK21) formed non-fuzzy colonies ( $f$ ). Bar, $1 \mathrm{~mm}$.

osmostressing agents also reduces the amount of flocculation. Hence, the effects of osmostress upon the flocculation of the $\Delta c a b k 1$ mutant appears to be indirect.

Colony phenotypes on solid media were also evaluated on medium 199 at $\mathrm{pH} 3.5$ and 7.5 (Fig. 5a-f). We observed that the control and heterozygote strains at $\mathrm{pH} 7.5$ produced colonies with hyphae emerging from the periphery of the colonies (Fig. Sb and d), but the null strain formed non-fuzzy colonies (Fig. 5f). Microscopic observations of the $\Delta c a b k 1$ null strain from non-fuzzy colonies revealed that these contained filamentous cells as well as an extensive aggregation of hyphae similar to that observed in liquid media. At $\mathrm{pH} \mathrm{3.5,} \mathrm{the} \Delta c a b k 1$ mutants formed smooth-edged colonies and grew similarly to CAF2 (Fig. 5a, c and e).

To study the invasiveness of agar of the $\Delta c a h k 1$ mutants in comparison with the control strain (CAF2), we grew these strains in SLAD medium, which promotes pseudohyphal formation, as described by Csank et al. (1998). However, no differences between the control strain and the $\Delta c a b k 1$ null strain were observed.

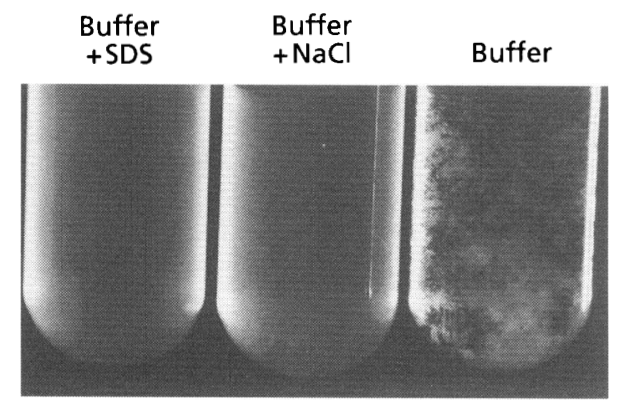

Fig. 6. Inhibition of flocculation by SDS and $\mathrm{NaCl}$. Cells of a $\Delta$ cahk1 mutant were prepared as described in the text. Cells were resuspended in a buffer $(10 \mathrm{mM}$ Tris/ $\mathrm{HCl}, \mathrm{pH} 8.0,2 \mathrm{mM}$ EDTA) without additives, in which they flocculate (right). The addition of $4 \%(w / v)$ SDS (final concentration) inhibits flocculation (left) but the addition of $5 \mathrm{M} \mathrm{NaCl}$ (final concentration) partially inhibits flocculation (middle). The addition of other additives such as DTT, mannose, glucose or maltose had no effect on flocculation. Cell suspensions incubated in the presence of these additives appeared as pictured on the right.

Finally, the strain reconstituted for one allele (CHK23), in liquid medium 199 at $\mathrm{pH} 3.5$ also grew as yeast and at $\mathrm{pH} 7.5$ flocculated less than the $\Delta c a b k 1$ null strain (CHK21), but similar to the heterozygote strain (CHK11) (Fig. 4a). Also, the microscopic appearance and the morphology of the colonies in medium 199 at $\mathrm{pH} 3.5$ and 7.5 were similar to that of the heterozygote (CHK11) (Fig. 5g and $\mathrm{h}$ ). This indicated that the flocculation-like phenotype that was exhibited by the $\Delta$ cabk1 null strain was really due to the absence of CaHK1 and not to additional mutations that could be introduced during the disruption process.

Additional studies were carried out to quantify the rate of flocculation in the mutants compared to control strains using the method described by Miki et al. (1982a, b) for flocculation in $S$. cerevisiae. We used several putative inhibitors of flocculation mediated by lectinlike interactions such as $1 \mathrm{M}$ mannose, $1 \mathrm{M}$ glucose and $1 \mathrm{M}$ maltose, and other inhibitors that disrupt proteinprotein interactions such as $5 \mathrm{M} \mathrm{NaCl}, 50 \mathrm{mM}$ DTT and $4 \%(\mathrm{w} / \mathrm{v})$ SDS. To do these experiments, stationary-phase cells from each strain grown in YPD were used as inoculum in medium 199 ( $\mathrm{pH} \mathrm{7 \cdot 5).} \mathrm{After}$ $3 \mathrm{~h}$ culture at $37^{\circ} \mathrm{C}$, the cells were collected, washed twice in $10 \mathrm{mM}$ Tris/ $\mathrm{HCl} \mathrm{pH} 8.0$ and $2 \mathrm{mM}$ EDTA, and resuspended in the same buffer containing inhibitors of flocculation at the final concentrations described above. The addition of $\mathrm{CaCl}_{2}$ was not required for flocculation. Unfortunately, the experiments to quantify the flocculation were unsuccessful due to the dramatic flocculation which normally occurred with the null strain. Only visual observations to determinate if flocculation was or was not inhibited could be performed. Thus, the inhibitor studies showed that only SDS totally inhibited flocculation and $\mathrm{NaCl}$ partially inhibited this process (Fig. 6), while other inhibitors did not have any effect, indicating that flocculation may be caused by a proteinprotein interaction rather than a lectin-like interaction 


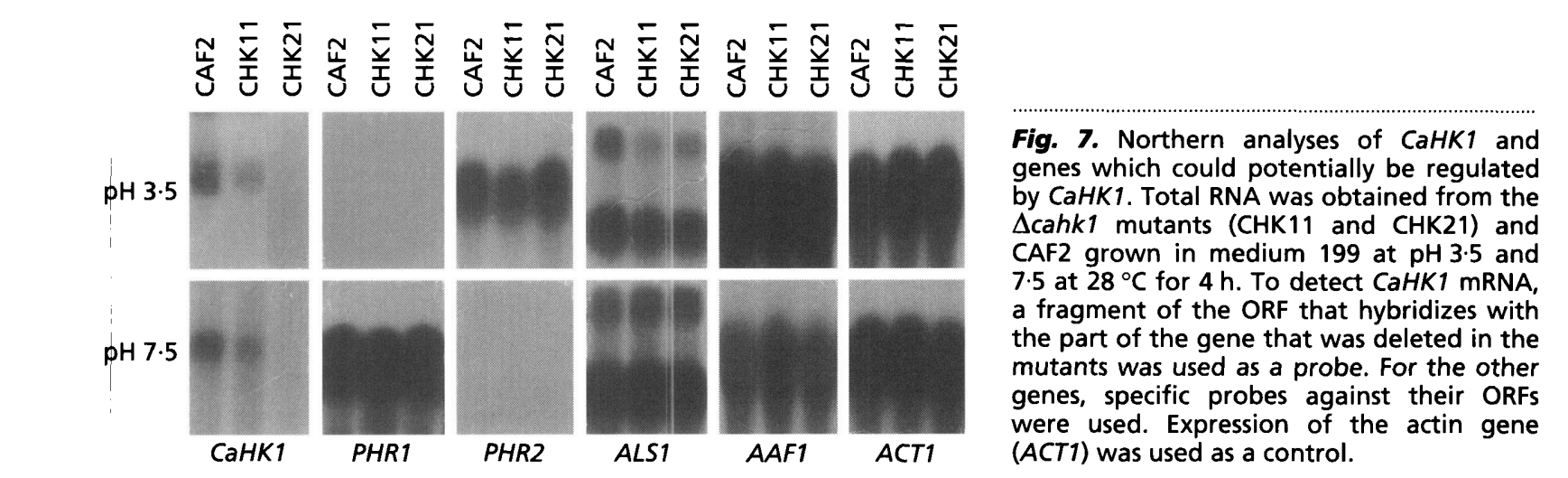

since flocculation was totally or partially inhibited by compounds that disrupt protein-protein interactions. However, this does not preclude that additional molecular mechanisms could be responsible for flocculation. Also, the mechanisms that mediate hyphal flocculation seem to be different from those in $S$. cerevisiae. Flocculation in $S$. cerevisiae is mediated by the FLO1 gene and is $\mathrm{Ca}^{2+}$-dependent (Miki et al., 1982a, b). In contrast, flocculation in the $\Delta c a b k 1$ null strain of $C$. albicans was not $\mathrm{Ca}^{2+}$-dependent.

\section{Northern analysis of CaHK1 expression and other genes whose expression could be potentially regulated by $\mathrm{CaHK1}$}

As growth differences (flocculation) were seen when the disrupted strains were grown in medium 199 at $\mathrm{pH} 7 \cdot 5$, we chose this medium to study the expression of CaHK1 and several other genes whose expression could be potentially under the control of CaHK1. Since flocculation appeared to be related to the $\mathrm{pH}$ of the culture media, we measured the expression of $\mathrm{CaHK} 1$ at $\mathrm{pH} 3.5$ and 7.5. Also, we measured the expression of $\mathrm{pH}$ regulated genes such as $P H R 1$ and $P H R 2$ (Muhlschlegel \& Fonzi, 1997; Saporito-Irwin et al., 1995) in the $\Delta c a b k 1$ mutants. Likewise, since flocculation could be related to an altered expression of proteins involved in adhesion, we also tested ALS1, whose encoded protein (Hoyer et al., 1995) has been associated with adhesion (Fu et al., 1998a). Finally, we tested whether the expression of the CAD1/AAF1 gene from C. albicans, which has recently been reported to confer a Flo1-like phenotype when it is expressed in S. cerevisiae (Fu et al., 1998b), was under the control of CaHK1. We performed these experiments using RNA obtained from control (CAF2) and $\mathrm{Ura}^{+}$ disrupted strains (CHK11 and CHK21) grown in medium 199 either at $\mathrm{pH} 7.5$ or $\mathrm{pH} 3.5$ at both 28 and $37^{\circ} \mathrm{C}$ for $4 \mathrm{~h}$. The results showed that CaHK1 is expressed in medium 199 either at $\mathrm{pH} 3.5$ or $\mathrm{pH} 7.5$ at both 28 and $37^{\circ} \mathrm{C}$. According to the signal on Northern blots, the heterozygote mutant showed a signal weaker than CAF2, corresponding to a smaller amount of mRNA; no expression was detected in the CHK21 null strain (Fig. 7). Those genes whose expression could be putatively altered in the $\Delta c a b k 1$ mutants showed the same pattern of expression that was previously reported for all of them (Muhlschlegel \& Fonzi, 1997; Saporito-Irwin et al., 1995; Hoyer et al., 1995; Fu et al., 1998b), and no changes in their expression were seen in the $\Delta c a b k 1$ background (Fig. 7).

\section{DISCUSSION}

We have recently reported the isolation and cloning of the CaHK1 histidine-kinase gene from C. albicans (Calera et al., 1998). As with many other histidine kinases, Cahk1p also shows homology with the Cterminal domain of CaSln1p and CaNik1p (Alex et al., 1998; Nagahashi et al., 1998), however, this homology is less than that seen with several prokaryotic histidine kinases. Thus, the strongest similarity with Cahk1p is a 1261 aa histidine kinase from the cyanobacterium Synechocystis (GenBank accession no.: D90910); again, this similarity is confined to the C-terminus of this protein. Recently, we have observed that a putative 2310 aa histidine kinase from $S$. pombe (Sphk1) exhibited the highest overall homology with Cahk1p. To date, the Ser/Thr-homologous domains, the P-loop motif, the histidine and aspartyl domains, as well as their relative positions are conserved in both Cahk1p and Sphk1. Unfortunately, no information is available about the role of Sphk1 in S. pombe. However, it is possible that these sequences may act as sensor domains for an unknown stimulus. On the other hand, all of the sensor histidine kinases described so far involved in the detection of environmental stimuli have hydrophobic domains which are used to anchor the protein to the plasma membrane so that the sensor domain is exposed on the outside of the membrane to sense the environmental stimulus. Cahk1p as well as Sphk1 do not have, according to their amino acid sequences, any hydrophobic domains that could span the membrane. Thus, the stimuli they detect may be cytoplasmic. The way in which this stimulus is sensed is unknown, but even an autophosphorylation process in their $\mathrm{N}$-terminal domains can not be precluded. In this regard, phytochromes from plants, which at their C-terminal domains look like histidine kinases, are presumably activated by autophosphorylation in a serine residue located at their $\mathrm{N}$-terminal domains (Elich \& Chory, 1997). In addition, although the $\mathrm{N}$-terminal domain of Cahk1p does not show homology with the I-IV domains of Ser/Thr 
kinases, which are primarily involved in anchoring and orienting the nucleotide (ATP/GTP) (Hanks \& Hunter, 1995), the P-loop, which is located close to the homologous VI-XI domains in Cahk $1 \mathrm{p}$ could bind the appropriate nucleotide.

Chromosomal mapping led us to locate $\mathrm{CaHK1}$ on chromosome 2 with its stop codon near to the stop codon of CaHOG1. Thus, CaHK1 and CaHOG1 are transcribed in opposite directions, sharing the same terminator sequence. In $S$. cerevisiae, $S \ln 1 p$ acts as an osmosensor in the HOG pathway in which Hoglp participates as a MAPK (mitogen-acivated protein kinase) involved in activating the synthesis of glycerol (Posas et al., 1996). The C. albicans homologue of this MAPK (CaHog1p) has been identified also as a MAPK involved in the synthesis of glycerol, the major osmoprotectant in $C$. albicans against hyperosmotic conditions (San Jose et al., 1996). The close proximity of these two genes in the genome of $C$. albicans led us to suppose a cluster-like arrangement of these genes. However, no effects on the growth of the $\Delta c a b k 1$ null strain were seen in hyperosmotic media. Thus, it seems that the close proximity of these genes on the chromosome does not have any apparent functional consequence.

The most obvious effect of the CaHK1 deletion is that cells flocculate extensively under conditions that stimulate germ-tube formation. Microscopic observations revealed that flocculation occurs primarily because of the interaction of hyphal surfaces in the $\Delta c a b k 1$ null but not in the control strain. However, flocculation not only occurs in liquid media, but also when cells are grown on solid medium 199 at $\mathrm{pH} 7.5$. In fact, this observation is strongly supported by the morphology of the colonies of the $\Delta c a b k 1$ null strain on solid medium. This strain forms non-fuzzy colonies probably because the flocculation, which occurs within the colonies, does not allow cells to grow normally and form fuzzy colonies as in the control, even though germination of the $\Delta c a b k 1$ null strain readily occurred.

On the other hand, in the presence of $\mathrm{NaCl}$ or sorbitol, the $\Delta c a b k 1$ null strain does not flocculate as extensively as in absence of osmostressing agents in the medium. This observation is actually what we would expect if we consider that high osmolarity inhibits hyphal development in the wild-type strains of C. albicans (Alex et al., 1998). Thus, as reported for CaNIK1/COS1 (Alex et al., 1998), such differences between the wild-type and mutants are difficult to assess. However, even though the effect of osmostress upon the flocculation of the $\Delta c a b k 1$ mutants seems to be indirect, the reduced elongation of the germ tubes from the $\Delta c a b k 1$ mutants in presence of osmostressing agents indicates that we can not totally preclude the possibility that $\mathrm{CaHK} 1$ could have some effect in osmosensing. In fact, the phenotype observed on solid surfaces could be due to an osmoticlike effect.

Many components of the C. albicans cell wall have been assigned an adhesion function (Chaffin et al., 1998).
Among these are the agglutinin-like proteins such as those of the ALS family or others like Aaflp, which recently has been reported more likely to be a transcription factor (Fu et al., 1998b) than a cell-wallassociated protein. Recently, experiments that involved the expression of the ALS1 and AAF1 in S. cerevisiae have reported that both genes enhance adherence of $S$. cerevisiae to epithelial and endothelial cells, respectively (Fu et al., 1998a, b). Expression of AAF1, which is known to be an aggregation factor, stimulates endothelial cell adherence by inducing a flocculation phenotype similar to the Flo1 phenotype of $S$. cerevisiae (Fu et al., 1998b). However, according to the results obtained by Northern analysis in our studies, Als1p (a cell surface protein) and Aaflp (a potential transcription factor) do not seem to be the components associated with the flocculation-like phenotype, since their level of expression is not altered in the disrupted strains. Nevertheless, other cell-wall components have been described whose expression could potentially be regulated by CaHK1, such as Alalp (Gaur \& Klotz, 1997), Hwp1p (Staab et al., 1996), Als3p (Hoyer et al., 1998) or any other member of the ALS family. In addition, expression of PHR1 and PHR2, both $\mathrm{pH}$ regulated (Muhlschlegel \& Fonzi, 1997; Saporito-Irwin et al., 1995) were also not affected by the $\Delta c a b k 1$ null mutation. However, other $\mathrm{pH}$-regulated genes may exist in C. albicans which could potentially be under the control of $\mathrm{CaHK} 1$. Finally, the expression of $\mathrm{CaHK} 1$ is not dependent on $\mathrm{pH}$, temperature or growth morphology. However, even though CaHK1 could be regulated at the translational level, it seems more than likely that, as with other sensor histidine kinases involved in detection of environmental changes, the activity of Cahk1p could be modulated by its state of phosphorylation rather than by the expression of CaHK1.

In conclusion, our results indicate that $\mathrm{CaHK1}$ may be involved in the regulation of the expression of at least one hyphal-surface component, since the $\Delta c a b k 1$ null strain flocculates more extensively than the control strain under those conditions which induce hyphal formation (growth in medium 199, $\mathrm{pH} 7 \cdot 5$ ). This also is an indication that changes in the development of hyphae have occurred upon the deletion of $\mathrm{CaHK1}$. Finally, we can not preclude the possibility that Cahk1p could act as an internal $\mathrm{pH}$ sensor used by cells as a signal to trigger the synthesis of hyphal surface components or even play some role in osmosensing. Ongoing investigations in our lab. are focused upon the identification of genes that are differentially displayed between the control strain and the $\Delta c a b k 1$ null strain under those conditions that induce germ-tube formation.

\section{ACKNOWLEDGEMENTS}

This work was supported by a Public Health Service Grant to R.C. (NIH-NIAID-POIAI37751). J.A.C. is a recipient of a postdoctoral fellowship from the Ministerio de Educación y Cultura of the Spanish government. We also thank Scott Filler 
for the ALS1 probe and William Fonzi for the PHR1 and PHR 2 probes.

\section{REFERENCES}

Alex, L. A., Borkovich, K. A. \& Simon, M. I. (1996). Hyphal development in Neurospora crassa: involvement of a twocomponent histidine kinase. Proc Natl Acad Sci USA 93, $3416-3421$

Alex, L. A., Korch, C., Selitrennikoff, C. P. \& Simon, M. I. (1998). COS1, a two-component histidine kinase that is involved in hyphal development in the opportunistic pathogen Candida albicans. Proc Natl Acad Sci USA 95, 7069-7073.

Altschul, S. F., Gish, W., Miller, W., Myers, E. W. \& Lipman, D. J. (1990). Basic local alignment search tool (BLAST). J Mol Biol 215, 403-410.

Banuett, F. (1998). Signalling in the yeasts: an informational cascade with links to the filamentous fungi. Microbiol Mol Biol Rev 62, 249-274.

Calera, J. A., Choi, G. H. \& Calderone, R. (1998). Identification of a putative histidine kinase two-component phosphorelay gene (CaHK1) in Candida albicans. Yeast 14, 665-674.

Chaffin, W. L., Lopez-Ribot, J. L., Casanova, M., Gozalbo, D. \& Martinez, J. P. (1998). Cell wall and secreted proteins of Candida albicans: identification, function, and expression. Microbiol Mol Biol Rev' 62, 130-180.

Chang, W. T., Thomason, P. A., Gross, J. D. \& Neweil, P. C. (1998). Evidence that the RdeA protein is a component of a multistep phosphorelay modulating rate of development in Dictyostelium. $E M B O /$ 17, 2809-2816.

Csank, C., Schroppel, K., Leberer, E., Harcus, D., Mohamed, O., Meloche, S., Thomas, D. Y. \& Whiteway, M. (1998). Roles of the Candida albicans mitogen-activated protein kinase homolog, Cek $1 \mathrm{p}$, in hyphal development and systemic candidiasis. Infect Immun 66, 2713-2721.

Cottarel, G. (1997). Mcs4, a two-component system response regulator homologue, regulates the Schizosaccharomyces pombe cell cycle control. Genetics 147, 1043-1051.

Elich, T. D. \& Chory, J. (1997). Phytochrome: if it looks and smells like a histidine kinase, is it a histidine kinase? Cell 91, 713-716.

Fonzi, W. A. \& Irwin, M. Y. (1993). Isogenic strain construction and gene mapping in Candida albicans. Genetics 134, 717-728.

Fu, Y., Rieg, G., Fonzi, W. A., Belanger, P. H., Edwards, J. E. \& Filler, S. G. (1998a). Expression of the Candida albicans gene ALS1 in Saccharomyces cerevisiae induces adherence to endothelial and epithelial cells. Infect Immun 66, 1783-1786.

Fu, Y., Filler, S. G., Spellberg, B. J., Fonzi, W., Ibrahim, A. S., Kanbe, T., Ghannoum, M. A. \& Edwards, J. E. (1998b). Cloning and characterization of CAD1/AAF1, a gene from Candida albicans that induces adherence to endothelial cells after expression in Saccharomyces cerevisiae. Infect Immun 66, 2078-2084.

Gaur, N. K. \& Klotz, S. A. (1997). Expression, cloning, and characterization of a Candida albicans gene, ALA1, that confers adherence properties upon Saccharomyces cerevisiae for extracellular matrix proteins. Infect Immun 65, 5289-5294.

Gietz, D., Jean, A., Woods, R. A. \& Schiestl, R. H. (1991). Improved method for high efficiency transformation of intact yeast cells. Nucleic Acids Res 20, 1425.

Hanks, S. K. \& Hunter, T. (1995). Protein kinases 6. The eukaryotic protein kinase superfamily: kinase (catalytic) domain structure and classification. FASEB J 9, 576-596.
Hoch, J. A. \& Silhavy, T. J. (1995). Two-Component Signal Transduction. Washington, DC: American Society for Microbiology.

Hoyer, L. L., Scherer, S., Shatzman, A. R. \& Liv, G. P. (1995). Candida albicans ALS1: domains related to a Saccharomyces cerevisiae sexual agglutinin separated by a repeating motif. Mol Microbiol 15, 39-54.

Hoyer, L. L., Payne, T. L., Bell, M., Myers, A. \& Scherer, S. (1998). Candida albicans ALS3 and insights into the nature of the ALS gene family. Curr Genet 33, 451-459.

Miki, B. L., Poon, N. H., James, A. P. \& Seligy, V. L. (1982a). Possible mechanism for flocculation interactions governed by gene FLO1 in Saccharomyces cerevisiae. J Bacteriol 150, 878-889.

Miki, B. L., Poon, N. H. \& Seligy, V. L. (1982b). Repression and induction of flocculation interactions in Saccharomyces cerevisiae. J Bacteriol 150, 890-899.

Morgan, B. A., Banks, G. R., Toone, W. M., Raitt, D., Kuge, S. \& Johnston, L. H. (1997). The $\mathrm{Skn} 7$ response regulator controls gene expression in the oxidative stress response of the budding yeast Saccharomyces cerevisiae. EMBO J 16, 1035-1044.

Muhlschlegel, F. A. \& Fonzi, W. A. (1997). PHR2 of Candida albicans encodes a functional homolog of the $\mathrm{pH}$-regulated gene PHR1 with an inverted pattern of $\mathrm{pH}$-dependent expression. Mol Cell Biol 17, 5960-5967.

Nagahashi, S., Mio, T., Ono, N., Yamada-Okabe, T., Arisawa, M., Bussey, H. \& Yamada-Okabe, H. (1998). Isolation of CaSLN1 and CaNIK1, the genes for osmosensing histidine kinase homologues, from the pathogenic fungus Candida albicans. Microbiology 144, $425-432$.

Parkinson, J. S. (1993). Signal transduction schemes of bacteria. Cell 73, 857-871.

Posas, F., Wurgler-Murphy, S. M., Maeda, T., Witten, E. A., Thai, T. C. \& Saito, H. (1996). Yeast HOG1 MAP kinase cascade is regulated by a multistep phosphorelay mechanism in the SLN1YPD1-SSK1 'two-component' osmosensor. Cell 86, 865-875.

Sambrook, J., Fritsch, E. F. \& Maniatis, T. (1989). Molecular Cloning: a Laboratory Manual, 2nd edn. Cold Spring Harbor, NY: Cold Spring Harbor Laboratory.

San Jose, C., Monge, R. A., Perez-Diaz, R., Pla, J. \& Nombela, C. (1996). The mitogen-activated protein kinase homolog HOG1 gene controls glycerol accumulation in the pathogenic fungus Candida albicans. J Bacteriol 178, 5850-5852.

Saporito-Irwin, S. M., Birse, C. E., Sypherd, P. S. \& Fonzi, W. A. (1995). PHR1, a pH-regulated gene of Candida albicans, is required for morphogenesis. Mol Cell Biol 15, 601-613.

Saraste, M., Sibbald, P. R. \& Wittinghofer, A. (1990). The P-loop, a common motif in ATP- and GTP-binding proteins. Trends Biochem Sci 15, 430-434.

Schuster, S. C., Noegel, A. A., Oehme, F., Gerisch, G. \& Simon, M. I.(1996). The hybrid histidine kinase DokA is part of the osmotic response system of Dictyostelium. EMBO J 15, 3880-3889.

Sherman, F., Fink, G. R. \& Hicks, J. B. (1986). Methods in Yeast Genetics. Cold Spring Harbor, NY: Cold Spring Harbor Laboratories.

Shieh, J. C., Wilkinson, M. G., Buck, V., Morgan, B. A., Makino, K. \& Millar, J. B. (1997). The Mcs4 response regulator coordinately controls the stress-activated Wak1-Wis1-Sty1 MAP kinase pathway and fission yeast cell cycle. Genes Dev 11, 1008-1022.

Staab, J. F., Ferrer, C. A. \& Sundstrom, P. (1996). Developmental expression of a tandemly repeated, proline- and glutamine-rich amino acid motif on hyphal surfaces of Candida albicans. J Biol Chem 271, 6298-6305. 
Wang, N., Shaulsky, G., Escalante, R. \& Loomis, W. F. (1996). A two-component histidine kinase gene that functions in Dictyostelium development. EMBO J 15, 3890-3898.

Wickes, B. L., Golin, J. E. \& Kwon-Chung, K. J. (1991). Chromosomal rearrangement in Candida stellatoidea results in a positive effect on phenotype. Infect Immun 59, 1762-1771.
Zinda, M. J. \& Singleton, C. K. (1998). The hybrid histidine kinase $\mathrm{dhkB}$ regulates spore germination in Dictyostelium discoideum. Dev Biol 196, 171-183.

Received 22 October 1998; revised 10 December 1998; accepted 3 February 1999. 